\title{
Correction \\ Correction: Ultrasonography, magnetic resonance imaging, radiography, and clinical assessment of inflammatory and destructive changes in fingers and toes of patients with psoriatic arthritis
}

\author{
Charlotte Wiell1, Marcin Szkudlarek ${ }^{1}$, Maria Hasselquist ${ }^{2}$, Jakob M Møller², Aage Vestergaard ${ }^{3}$, \\ Jesper Nørregaard ${ }^{4}$, Lene Terslev ${ }^{5}$ and Mikkel Østergaard ${ }^{1,5}$
}

\begin{abstract}
1'Department of Rheumatology, University of Copenhagen Hvidovre Hospital, Kettegaard Allé 30, 2650 Hvidovre, Denmark 2Department of Diagnostic Radiology, University of Copenhagen Herlev Hospital, Herlev Ringvej 75, 2730 Herlev, Denmark 3Department of Radiology, University of Copenhagen Hvidovre Hospital, Kettegaard Allé 30, 2650 Hvidovre, Denmark 4Department of Rheumatology, University of Copenhagen Nordsjællands Hørsholm Hospital, Usserød Kongevej 102, 2970 Hørsholm, Denmark ${ }^{5}$ Department of Rheumatology, University of Copenhagen Herlev Hospital, Herlev Ringvej 75, 2730 Herlev, Denmark
\end{abstract}

Corresponding author: Charlotte Wiell, charlottewiell@dadlnet.dk

Published: 22 January 2008

Arthritis Research \& Therapy 2008, 10:402 (doi:10.1186/ar2356)

This article is online at http://arthritis-research.com/content/10/1/402

(c) 2008 BioMed Central Ltd

See related research article by Wiell et al., http://arthritis-research.com/content/9/6/R119

After publication of our recent article [1], we noticed several errors within the article which are corrected below:

In the third sentence of the Introduction, the citation should read [6-9], and in the fourth sentence the citation [8-9] should be removed.

In the Materials and Methods section, under the heading 'Ultrasonography', in the 13th sentence, $12 \mathrm{~mm}$ should read as $1.2 \mathrm{~mm}$.

In the Results section, under the heading 'Ultrasonography observations in PsA and RA patients and CTRLs', in the 6th sentence, $12 \mathrm{~mm}$ should read as $1.2 \mathrm{~mm}$ and $20 \mathrm{~mm}$ should read as $2.0 \mathrm{~mm}$

In the Discussion the following section of the second paragraph:

In this study, US revealed synovitis more frequently in MCP and PIP joints and bone erosions less frequently in PIP joints in the RA group than in the PsA group, whereas Fournié and colleagues [13] reported minimal differences in the amount of erosion and synovitis in MCP and PIP joints of PsA and RA patients. Fournié and colleagues [13], as in our study, reported more tenosynovitis and a few osteoarthritic changes (2 of 21 patients) in the RA group and only erosive DIP joint changes in the PsA group. However, they exclusively found extrasynovial changes in PsA patients, which we also detected in 3 of the 5 RA patients (60\% confirmed by MRI). Larger studies are required to provide final conclusions.
Should read as:

In this study, US revealed synovitis more frequently in MCP and PIP joints and bone erosions less frequently in PIP joints in the RA group than in the PsA group. Fournié and colleagues [13] reported more erosions and synovitis in joints of RA patients than in PsA patients. The authors [13], as in our study, reported more tenosynovitis and a few osteoarthritic changes (2 of 21 patients) in the RA group and only erosive DIP joint changes in the PsA group. However, they exclusively found extrasynovial changes in PsA patients, which we also detected in 3 of the 5 RA patients $(60 \%$ confirmed by MRI). Their definitions of extrasynovial abnormalities are different than ours which could explain the differences in the results. Larger studies are required to provide final conclusions.

\section{Reference}

1. Wiell C, Szkudlarek M, Hasselquist M, Møller JM, Vestergaard A, Nørregaard J, Terslev L, Ostergaard M: Ultrasonography, magnetic resonance imaging, radiography, and clinical assessment of inflammatory and destructive changes in fingers and toes of patients with psoriatic arthritis. Arthritis Res Ther 2007, 9:R119. 